\title{
Editorial
}

\section{Lessons from myocardial contrast echocardiography studies during primary angioplasty}

Early recanalisation of an occluded coronary artery to achieve timely myocardial reperfusion is the main goal of treatment of myocardial infarction during the acute phase. Successful recanalisation has generally been defined as the angiographic demonstration of early and complete (TIMI-3 flow) patency of the infarct related artery; however, angiography has serious limitations for judging of the efficacy of reperfusion treatment. ${ }^{1}$ In particular, patients with a widely patent epicardial coronary vessel often demonstrate lack of adequate myocardial perfusion, most likely because of microvascular injury. This "noreflow" phenomenon was first described in 1974 by Kloner et al in an animal model, ${ }^{2}$ and observed in man in 1992 by Ito et al using intracoronary myocardial contrast echocardiography (MCE) performed during primary angioplasty (PTCA) for acute myocardial infarction. ${ }^{3}$ Taking advantage of the access to the coronary circulation offered during primary PTCA, this technique relies on direct intracoronary injection of contrast agents containing microbubbles, often using simple sonicated radio-opaque dyes. Simultaneous echocardiography allows opacification of the perfused myocardium through reflection of ultrasonic energy by the air containing microbubbles located in the myocardial microvasculature (fig 1 ).

\section{Usefulness of MCE in acute myocardial infarction} Echocardiographic studies performed in the catheterisation laboratory during primary PTCA have demonstrated that even in patients with widely patent coronary arteries, no-reflow may be present in up to $37 \%$ of cases, and is a major poor prognostic factor. ${ }^{3-5}$ These patients experience decreased left ventricular regional contractile function recovery, increased left ventricular remodelling, an increased rate of clinical adverse events (such as pericardial effusion, ventricular arrhythmias, pulmonary oedema), and a trend towards increased mortality. ${ }^{4}$ In fact, recovery of left ventricular function and dimensions appear as poor as those observed in patients with TIMI- 2 flow. ${ }^{5}$ More recent studies $^{67}$ have established that normal myocardial perfusion in the myocardial area at risk, as assessed by MCE immediately after re-establishment of coronary patency, is in fact a prerequisite for both early and delayed recovery of segmental wall motion after acute myocardial infarction. There is strong evidence ${ }^{8-10}$ that the extent of maintained microvascular perfusion on MCE performed acutely correlates with the extent of myocellular viability (as assessed by contractile reserve under dobutamine and by delayed functional recovery).

\section{Technical developments}

The clinical future of MCE relies on the successful development of intravenously injectable contrast agents able to cross the pulmonary capillary bed, with low ultrasonic attenuation, enabling myocardial opacification of the myocardium. To yield the full potential of these agents, they have to be combined with new emerging ultrasound techniques such as second harmonic imaging, to increase the myocardial contrast enhancement, and intermittent imaging, which limits destruction of the contrast microbubbles

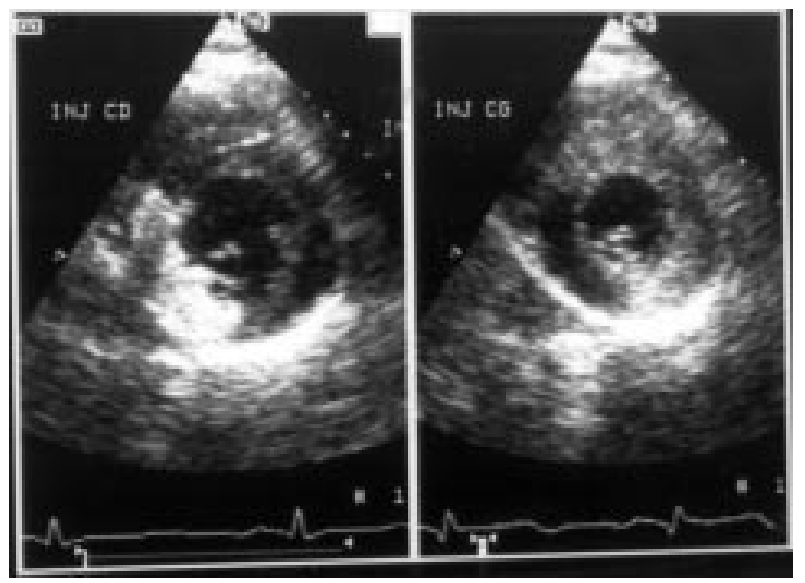

Figure 1 Left, short axis echocardiographic view of the left ventricle during injection of microbubbles (sonicated dye) into the right coronary artery ostium, 10 minutes after recanalisation in an inferior myocardial infarction. The injection clearly delineates a region of contrast enhancement corresponding to the myocardial area supplied by the recanalised right coronary, with probable hyperhemia. Right, same view after injection of sonicated dye into the left main coronary artery, demonstrating the complementary opacification of the left ventricle.

by ultrasound. Several experimental and clinical trials of intravenous contrast agents are ongoing using these new techniques, and will hopefully open the way for routine clinical use. Another issue is the requirement for objective and quantitative assessment of myocardial perfusion. This is especially important in the view of the potential limitation to the early assessment of myocardial perfusion in reperfused areas because of hyperaemia, which may take several hours to abate and may result in underestimation of the degree of myocardial necrosis.

\section{Perspectives}

The potential applications of MCE in acute myocardial infarction are far reaching. First, it may finally allow accurate and meaningful real-time non-invasive assessment of myocardial reperfusion after thrombolysis. Currently available thrombolytic regimens fail to achieve acute complete patency of the infarct vessel in nearly half the patients, who subsequently have a poor prognosis. Early non-invasive assessment of myocardial reperfusion is therefore important to identify rapidly high risk patients and to select candidates for adjunctive therapy, including emergency rescue PTCA. In addition, it may be used as a surrogate non-invasive end point to coronary angiography for the comparison of thrombolytic regimens, an important goal given the limitations, logistic burden, risks, and cost of angiography. Recently, intravenous contrast agents (perfluorocarbone exposed sonicated dextrose-albumin) have been used during MCE to evaluate the success of thrombolytic therapy in man. ${ }^{11}$ Porter et al have shown the presence of no-reflow in the vast majority of patients with no or incomplete patency (TIMI-0-2 flow), but also in a large subset of patients with TIMI-3 patency of the infarct vessel. Whether this should lead to adjunctive interventions such as rescue PTCA is yet unproven, but myocardial 
perfusion may be a more logical goal than coronary patency for reperfusion therapies. Future studies should evaluate whether treatment options should be selected on the basis of MCE findings obtained at the bedside rather than coronary angiography. ${ }^{12}$

MCE could be a powerful method for evaluation of the myocardial microvasculature, either after attempts at prevention of no-reflow or in trials of myocardial therapeutic angiogenesis. Several agents, such as adenosine ${ }^{13}$ or nicorandil ${ }^{14}$ have been shown to decrease substantially microvascular and myocardial injury after reperfusion, not only in experimental models but also in man, and would deserve MCE studies. Finally, in addition to classic end points such as mortality, patency or left ventricular function, MCE assessment of myocardial perfusion may prove helpful in dissecting out differences between reperfusion methods or agents (for example, primary angioplasty, thrombolytic agents), ${ }^{15} 16$ or adjunctive therapies (new antithrombotics, stents, etc). Agati et al have observed that MCE no-reflow is less frequent in patients treated by primary PTCA than in patients treated by thrombolysis. ${ }^{16}$

Studies using intracoronary injection of sonicated agents during primary PTCA have shown the potential of myocardial contrast echocardiography for the study of myocardial perfusion during acute infarction. These studies have underlined the importance and clinical relevance of the no-reflow phenomenon and underlined the importance of myocardial reperfusion as opposed to coronary recanalisation. The availability of intravenous agents and the parallel technical advances in echocardiographic imaging techniques show much promise for the non-invasive exploration of myocardial perfusion during acute myocardial infarction. This should help in real-time non-invasive risk stratification, in the selection of treatment options, as well as in the evaluation of new therapies.

DANIEL KARILA-COHEN DANIEL CZITROM ERIC BROCHET

Cardiology, Hôpital Bichat, PH GABRIEL STEG

75877 Paris Cedex 18, France
1 Lincoff AM, Topol EJ. Illusion of reperfusion. Does anyone achieve optimal reperfusion during acute myocardial infarction. Circulation 1993;87:1792805 .

2 Kloner RA, Ganote CE, Jennings RB. The "no-reflow" phenomenon after temporary coronary occlusion in the dog. F Clin Invest 1974;54:1496-508.

3 Ito H, Tomooka T, Sakai N, Yu H, Higashino Y, Fujii K, et al. Lack of myocardial reperfusion immediately after successful thrombolysis. Circulation 1992;85:1699-705.

4 Ito H, Maruyama A, Iwakura K, Takiuchi S, Masuyama T, Hori M, et al. Clinical implications of the "no reflow" phenomenon. A predictor of complications and left ventricular remodeling in reperfused anterior wall myocardial infarction. Circulation 1996;93:223-8.

5 Ito $\mathrm{H}$, Okamura A, Iwakura K, Masuyama T, Hori M, Takiuchi S, et al. Myocardial perfusion patterns related to thrombolysis in myocardial infarction perfusion grades after coronary angioplasty in patients with acute infarction perfusion grades after coronary angioplasty in patients
anterior wall myocardial infarction. Circulation 1996;93:1993-9.

6 Bolognese L, Antoniucci D, Rovai D, Buonamici P, Cerisano G, Santoro GM, et al. Myocardial contrast echocardiography versus dobutamine echocardiography for predicting functional recovery after acute myocardial infarction treated with primary coronary angioplasty. I Am Coll Cardiol 1996;28:1677-83.

7 Czitrom D, Karila-Cohen D, Brochet E, Seknadji P, Boccara A, Assayag P, et al. Heterogeneous reperfusion, assessed by myocardial contrast echocardiography during myocardial infarction, is associated with a substantial delayed recovery of wall motion [abstract]. F Am Coll Cardiol 1997; 29(suppl A):480A.

8 Ragosta M, Camarano GP, Kaul S, Powers ER, Sarembock ER, Gimple LW. Microvascular integrity indicates myocellular viability in patients with recent myocardial infarction. New insights using myocardial contrast echocardiography. Circulation 1994;89:2562-9.

9 Lim Y-J, Nanto S, Masuyama T, Kohama A, Hori M, Kamada T. Myocardial salvage: its assessment and prediction by the analysis of serial myocardial salvage: its assessment and prediction by the analysis of serial myocarAm Heart f 1994;128:649-56

10 Agati L, Voci P, Bilotta F, Luongo R, Autore C, Penco M, et al. Influence of residual perfusion within the infarct zone on the natural history of left ventricular dysfunction after acute myocardial infarction. A myocardial contrast echocardiographic study. F Am Coll Cardiol 1994;24:336-442.

11 Porter T, Li S, Deligonul U. Harmonic triggered imaging following intravenous ultrasound contrast in the assessement of patients following acute $\mathrm{MI}$ and thrombolytic therapy: implication of resting contrast defect [abstract]. I Am Coll Cardiol 1997;29(suppl A):479A

12 Himbert D, Seknadji P, Karila-Cohen D, Juliard JM, Steg PG. Myocardial contrast echocardiography to assess spontaneous reperfusion during myocardial infarction [letter]. Lancet 1997;349:617-19.

13 Marzilli M, Gliozheni E, Fedele S, Ungi I, Orsini E, Marraccini P. Beneficial effects of adenosine in acute MI [abstract]. $\mathcal{F}$ Am Coll Cardiol 1997;29(suppl A): 133A.

14 Sakata Y, Kodama K, Lim YJ, Ishikura F, Hirayama A. Restoration of myocardial blood flow and functional improvement in patients with acute myocardial infarction by a $\mathrm{K}^{+}$-ATP channel opener, nicorandil [abstract]. $\mathcal{F} \mathrm{Am}$ Coll Cardiol 1997;29(suppl A): 133A.

15 Czitrom D, Brochet E, Karila-Cohen D, Seknadji P, Juliard JM, Steg P, et al. Recovery of initially-impaired myocardial perfusion is frequent after primary PTCA for acute myocardial infarction [abstract]. $7 \mathrm{Am}$ Coll Cardiol 1997;29(suppl A): 133A

16 Agati L, Hickle P, Voci P, Darwish Y, Autore C, Feinstein SB. Direct coronary angioplasty versus thrombolytic therapy for acute myocardial infarction: impact on microvascular integrity and regional function [abstract]. Circulation 1996;94(suppl I):I575. 